\title{
Study on Energy Saving Technology of Night-time Illumination of Expressway Tunnel
}

\author{
Hua Kaicheng ${ }^{1, ~ *, ~ Z h a o ~ C h a o ~}{ }^{1}$, Liao Haomiao ${ }^{2}$, Xia Yangyuyu $^{3}$, Wang Zihao ${ }^{2}$ \\ ${ }^{1}$ Guangdong Province Road and Bridge Construction Development Co., Ltd, Qingyuan, China \\ ${ }^{2}$ College of Civil Engineering, Chongqing Jiaotong University, Chongqing, China \\ ${ }^{3}$ China Merchants Chongqing Communications Technology Research \& Design Institute Co., Ltd., Chongqing, China
}

\section{Email address: \\ 757471933@qq.com (Hua Kaicheng) \\ ${ }^{*}$ Corresponding author}

\section{To cite this article:}

Hua Kaicheng, Zhao Chao, Liao Haomiao, Xia Yangyuyu, Wang Zihao. Study on Energy Saving Technology of Night-time Illumination of Expressway Tunnel. Science Discovery. Vol. 8, No. 4, 2020, pp. 64-68. doi: 10.11648/j.sd.20200804.11

Received: July 21, 2020; Accepted: August 18, 2020; Published: August 25, 2020

\begin{abstract}
With the continuous expansion of the scale and number of highway tunnels in China, the power consumption of highway tunnel lighting has gradually become a huge amount for operating units. How to reduce the power consumption of lighting for highway tunnels has become an important issue for operating units. However, energy saving does not mean less or no lights, the premise must be to ensure the safety and comfort of driving in the tunnel. In this study, based on the light environment characteristics of the tunnel at night, the visual resolution level of the target obstacle in front of the road is judged by the human eye 's saccade time, and whether the reduction of road lighting brightness under the effect of the headlights will affect the driver 's visual resolution level. The results show that the turning on of the car's high beam lights has a certain effect on the driver's visual perception ability; when the average brightness of the road surface is $1.0 \mathrm{~cd} / \mathrm{m}^{2}$, the tester's saccade and fixation time on the target obstacle are less than $0.5 \mathrm{~cd} / \mathrm{m}^{2}$, But the driver has no significant difference in the resolution of the target obstacles under these two brightness levels; when the brightness of the road surface is $0.5 \mathrm{~cd} / \mathrm{m}^{2}$, the driver still has confidence in the situation ahead; it is recommended that the entrance and exit have a certain distance The tunnel brightness can be adjusted to $0.5 \mathrm{~cd} / \mathrm{m}^{2}$.
\end{abstract}

Keywords: Highway Tunnel, Night Lighting, Energy Saving, Road Brightness, Visual Resolution

\section{公路隧道夜间照明节能技术研究}

\author{
华开成 ${ }^{*}$, 赵超 ${ }^{1}$, 廖浩永 ${ }^{2}$, 夏杨于雨 ${ }^{3}$, 王子豪 ${ }^{2}$ \\ 1广东省路桥建设发展有限公司, 清远, 中国 \\ 重庆交通大学土木工程学院, 重庆, 中国 \\ ${ }^{3}$ 招商局重庆交通科研设计院有限公司隧道与地下工程分院，重庆，中国
}

\section{邮箱}

757471933@qq.com（华开成）

摘要：随着我国公路隧道规模和数量的不断扩大, 公路隧道照明的电能消耗逐渐成为运营单位的巨大负担, 如何减少 公路隧道的照明用电成为了运营单位需面对的一项重要问题。然而, 节能并不意味着少开灯或不开灯, 其前提必须是 保证隧道内行车的安全性和舒适性。本研究基于隧道夜间的光环境特性, 通过人眼对道路前方目标障碍物的视觉分辨 水平, 探究高速公路隧道夜间适宜的路面亮度水平。结果表明：汽车远光灯的开启对驾驶员的视觉察觉能力有一定影 响; 当路面的平均亮度为 $1.0 \mathrm{~cd} / \mathrm{m}^{2}$ 时, 试验者对目标障碍物的扫视及注视时间均小于 $0.5 \mathrm{~cd} / \mathrm{m}^{2}$ 时, 但驾驶员对这 2 个亮 
度等级下的目标障碍物的分辨能力无较大差别; 路面的亮度为 $0.5 \mathrm{~cd} / \mathrm{m}^{2}$ 时, 驾驶者对前方的情况仍然有信心; 建议入 口和出口的一定距离的隧道亮度可调至 $0.5 \mathrm{~cd} / \mathrm{m}^{2}$ 。

关键词：公路隧道，夜间照明，节能，路面亮度，视觉分辨水平

\section{1. 引言}

夜间行车不同于昼间, 车辆在隧道外部仅依靠车灯提 供光通量, 其他区域则无光线分布, 整个视野基本上处于 暗环境中，因此一旦隧道提供照明，驾驶员将在进入隧道 时遭遇明适应问题，在驶离隧道时遭遇暗适应问题[1-7]。 如果隧道夜间照明亮度值过高, 明暗适应问题则更加严重, 同时在运营实践中过度照明也会造成不必要的电能浪费; 相反, 如果一味地为了节能从而降低隧道照明亮度又很容 易导致驾驶人产生视觉疲劳, 带来严重安全隐患。针对隧 道夜间照明这一问题, 许多国家提出了明确的要求。如: 《美国隧道照明技术指南》建议隧道内的平均亮度应不低 于 $2.5 \mathrm{~cd} / \mathrm{m}^{2}$ 。《丹麦公路隧道照明指南》建议当隧道为存 在照明时隧道平均亮度为 $2 \mathrm{~cd} / \mathrm{m}^{2}$, 当隧道外道路存在照明 时隧道内的平均亮度要求为 $1.0 \mathrm{~cd} / \mathrm{m}^{2}$ 。我国的《公路隧道 照明设计细则》建议当隧道位于设置照明的路段时, 隧道 夜间照明的亮度应与该路段的亮度水平、均匀性、眩光指 数应与隧道外道路保持一致, 如果隧道外道路没有照明, 高速及一级公路隧道内的路面平均亮度应不低于 $1 \mathrm{~cd} / \mathrm{m}^{2}$, 二级及以下等级公路隧道路面亮度可取至 $0.5 \mathrm{~cd} / \mathrm{m}^{2}$ 。

然而, 上述隧道照明设计指导细则 (指南) 对夜间照 明亮度的要求都只是简单地取一个定值, 也并未考虑汽车 远光灯对隧道夜间光环境的影响。本研究基于隧道夜间的 光环境特性, 通过人眼对道路前方目标障碍物的视觉分辨 水平, 探究在保证行车安全条件下的高速公路隧道夜间适 宜的路面亮度水平。

\section{2. 隧道夜间光环境分析}

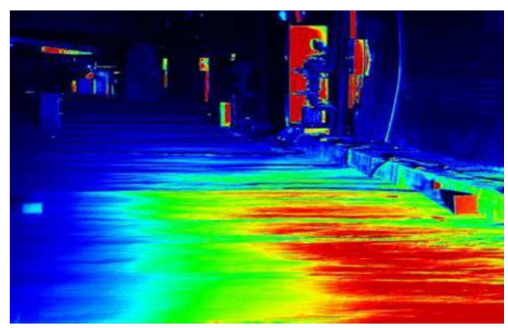

图1 长城SUV大灯亮度分布。

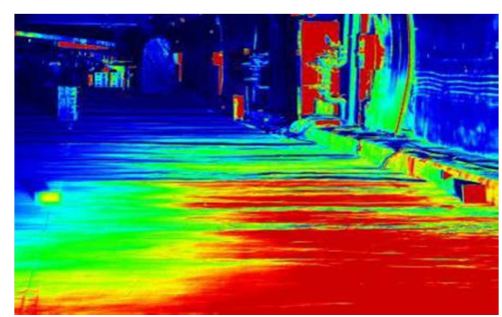

图2 大众高尔夫大灯亮度分布。
目前夜间行车车辆的前大灯基本上采用的为氙气灯, 在开启时具有一定的亮度, 为了掌握夜间行车辆大灯开启 时隧道路面的亮度等级, 采用成像式亮度计对不同类型车 辆的前大灯进行测试, 测试路面为混凝土路面, 取车辆前 方路面 20 米至 60 米、 60 米至 140 米两个区域的亮度值作为 参考, 部分测试情况如图1、图2所示。

从下表可以看出, 在车辆前方 20 米至 60 米的范围内, 路面的亮度一般在 $1 \mathrm{~cd} / \mathrm{m}^{2}$ 以上, 8 辆汽车的路面亮度平均 值为 $2.08 \mathrm{~cd} / \mathrm{m}^{2}$ 。在车辆前方 60 米至 140 米的范围内, 路面 的亮度一般在 $0.6 \mathrm{~cd} / \mathrm{m}^{2}$ 以上, 8 辆汽车的亮度平均值为 $0.59 \mathrm{~cd} / \mathrm{m}^{2}$ 。

表1 车前大灯下的路面亮度 $\left(\mathrm{cd} / \mathrm{m}^{2}\right)$ 。

\begin{tabular}{lll}
\hline 车辆类型 & 20-60米平均亮度 & $\mathbf{6 0 - 1 4 0}$ 米平均亮度 \\
\hline 长城SUV & 2.261 & 0.6468 \\
大众高尔夫 & 0.9527 & 0.2811 \\
沃尔沃V40 & 1.7016 & 0.5209 \\
丰田Prado & 3.8873 & 0.9914 \\
广汽传祺 & 2.9664 & 0.8319 \\
丰田汉兰达 & 2.0044 & 0.5990 \\
丰田凯美瑞 & 1.6057 & 0.4662 \\
起亚SUV & 1.331 & 0.3864 \\
\hline
\end{tabular}

如果路面为沥青路面, 其反射率低于混凝土路面 [8], 根据两种路面的反射率关系推算在沥青路面情况下车灯 的照明亮度, 前方 20 米至 60 米路面亮度一般在 $1.4 \mathrm{~cd} / \mathrm{m}^{2}$, 车辆前方 60 米至 140 米的范围内, 路面的亮度一般在 $0.4 \mathrm{~cd} / \mathrm{m}^{2}$ 以上。由此可见, 车灯对前方路面亮度的影响是 显著的。

\section{3. 实验方案设计}

本试验地点为隧道建设与养护技术交通行业重点实 验室的实体隧道, 隧道总长为200米, 共计两个行车道, 路面类型为水泥混凝土路面。通过比对试验者在不同路面 亮度情况下对前方路面目标障碍物的分辨能力探究适宜 的隧道夜间亮度水平。

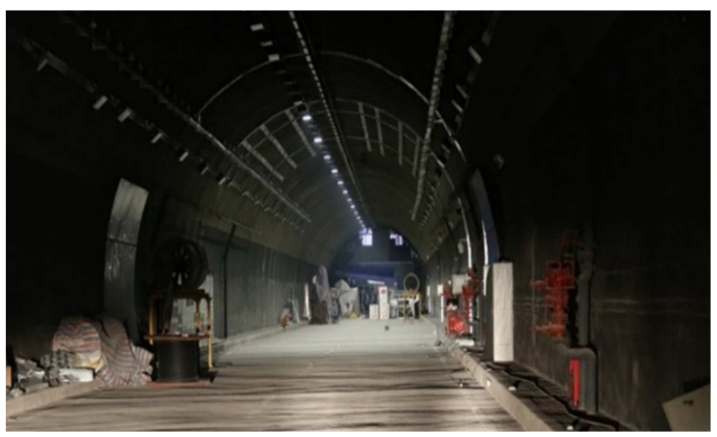

图3 试验隧道。 


\section{1. 试验场地布灯方案}

为了排除外界自然光线的干扰，所有试验安排在夜间 进行, 隧道内灯具布置方式为拱顶偏侧布灯, 全部采用 LED灯具, 间距可以根据需要调整为3米、6米、9米等。 LED灯具的色温为 $3984 \mathrm{~K}$, 显色性指数为 72.86 , 峰值波长 $450 \mathrm{~nm}$ ，主波长 $580 \mathrm{~nm}$ ，相对功率谱如下图4所示。

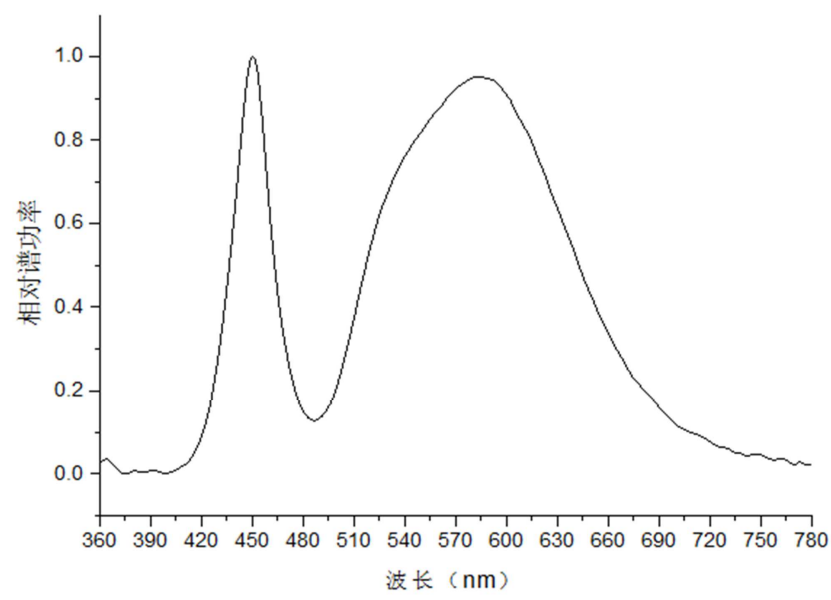

图4 灯具相对功率谱。

\section{2. 目标障碍物布置方案}

夜间采用的小目标物为黑色目标物, 放置于隧道路面, 其大小是按照美国道路照明标准 (RP-8-00) 建议的小目 标特征指标同比例计算 [9], 体积为 $0.008 \mathrm{~m}^{3}$ 。试验设计在 双车道路面等间距设置 5 个障碍小目标物, 距小目标物 100 米距离停滞一辆普通小汽车, 不同试验人员在该车内进行 试验。目标障碍物布置如图5所示。

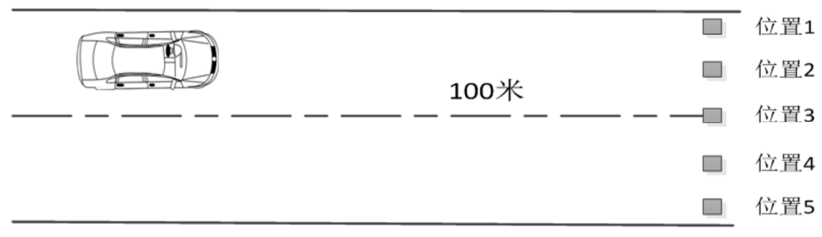

图5 目标障碍物布置。

\section{3. 路面亮度选取}

依据《公路隧道照明设计细则》规定可知我国高速及 一级公路隧道夜间照明亮度推荐值为 $1.0 \mathrm{~cd} / \mathrm{m}^{2}[10]$, 因此 将该亮度环境下的试验设为标准对照组[11]。试验组在标 准对照组亮度基础上降低二分之一, 取 $0.50 \mathrm{~cd} / \mathrm{m}^{2}$ 。

\section{4. 测试方法}

本次试验共计 18 人，其中男性 4 名、女性 4 名，平均年 龄为 23 岁, 测试采用的车辆为大众高尔夫。试验时安排不 同测试人员分批次进入试验车辆并佩戴眼动仪, 眼动仪可 记录人眼的注视时间、注视位置、眨眼次数、眼跳频率以 及睲孔变化速率等, 近年来广泛运用于交通安全相关的视
觉实验中[12-16]。通过计算机记录测试者的眼动数据同时 记录测试者的主观感受, 详细流程如图6所示。

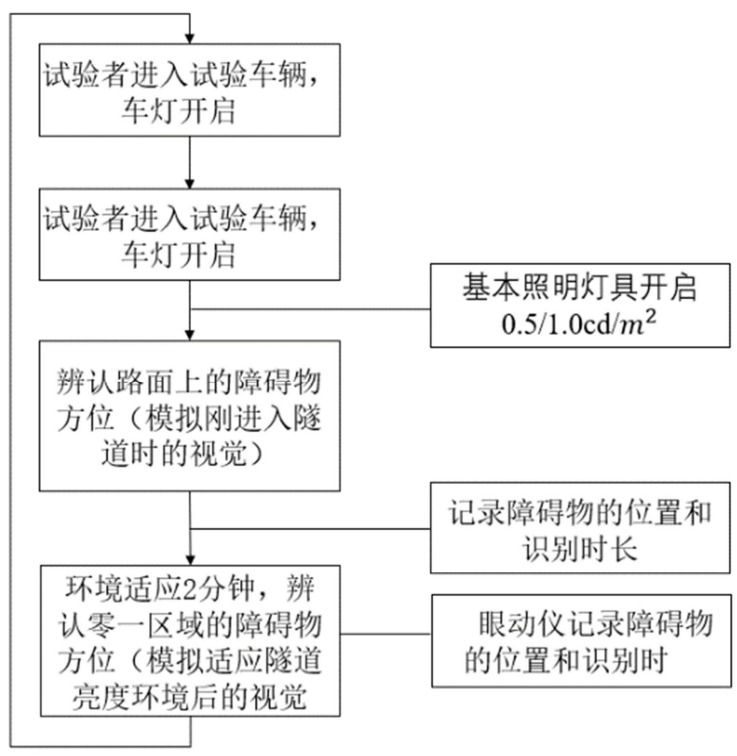

图6 试验详细流程。

\section{4. 实验结果}

本试验主要通过眼动仪记录测试者在远光灯开启和 关闭时眼睛对目标障碍物的扫视时间, 以扫视时间的长短 以及被测者主观感受为指标判断驾驶员的视觉分辨水平。 试验结果见表2、表3。

根据表 2 可知: 在 $1.0 \mathrm{~cd} / \mathrm{m}^{2}$ 的路面亮度下, 当关闭远光 灯时, 各试验者平均扫视时间和平均注视时间分别为 $157.41 \mathrm{~ms}$ 和 $74.91 \mathrm{~ms}$ (不包括未检测出具体时间的试验者, 下同），其中扫视时间小于 $100 \mathrm{~ms}$ 的试验者 6 名、注视时间 小于 $100 \mathrm{~ms}$ 的试验者 9 名; 当开启远光灯时各试验者平均扫 视时间和平均注视时间分别为 $161.71 \mathrm{~ms}$ 和 $81.64 \mathrm{~ms}$, 其中扫 视时间小于 $100 \mathrm{~ms}$ 的试验者 5 名、注视时间小于 $100 \mathrm{~ms}$ 的试 验者14名。

根据表 3 可知: 在 $0.5 \mathrm{~cd} / \mathrm{m}^{2}$ 的路面亮度下, 当关闭远光 灯时, 各试验者平均扫视时间和平均注视时间分别为 $161.71 \mathrm{~ms}$ 和 $96.5 \mathrm{~ms}$, 其中扫视时间小于 $100 \mathrm{~ms}$ 的试验者 6 名、注视时间小于 $100 \mathrm{~ms}$ 的试验者 12 名; 当开启远光灯时 各试验者平均扫视时间和平均注视时间分别为 $180.50 \mathrm{~ms}$ 和 $118.83 \mathrm{~ms}$, 其中扫视时间小于 $100 \mathrm{~ms}$ 的试验者 3 名、注视 时间小于 $100 \mathrm{~ms}$ 的试验者 14 名。

可以得知, 在同等亮度条件下, 开启远光灯时的扫视 时间和注视时间均要高于未开启远光灯时, 这说明远光灯 对驾驶员的视觉分辨能力有一定影响; 当车辆未开启远光 灯时, 在路面亮度 $1.0 \mathrm{~cd} / \mathrm{m}^{2}$ 的条件下驾驶员的平均扫视时 间及平均注视时间均略小于 $0.5 \mathrm{~cd} / \mathrm{m}^{2}$ 条件下, 但差距不大; 当车辆开启远光灯时, 在路面亮度 $1.0 \mathrm{~cd} / \mathrm{m}^{2}$ 的条件下驾驶 员的平均扫视时间及平均注视时间均略小于在 $0.5 \mathrm{~cd} / \mathrm{m}^{2}$ 条 件下。 


\section{5. 实验结论}

(1) 车辆远光灯开启时驾驶者对目标障碍物的察觉 和判断时间有所增加, 这是因为驾驶者对目标物障碍物的 觉察主要依赖于目标物与路面间的对比度, 当远光灯开启 时, 提高了小目标物垂直面的亮度, 而对路面的亮度提升 幅度较小, 从而降低了目标物与背景之间的对比度。实验 结果也验证了对比度理论的可靠性。

（2）当路面的平均亮度为 $1.0 \mathrm{~cd} / \mathrm{m}^{2}$ 时, 试验者对目标 障碍物的扫视及注视时间均小于 $0.5 \mathrm{~cd} / \mathrm{m}^{2}$ 时, 但整体变化 幅度均不超过 $50 \mathrm{~ms}$, 由此可确定驾驶员在这 2 个亮度等级 下的目标障碍物分辨能力无较大差别, 并不会对安全产生 明显影响。
（3）试验后根据实验者对两种不同亮度等级下前方 状况的主观评价, 路面平均亮度为 $1.0 \mathrm{~cd} / \mathrm{m}^{2}$ 时, 大多数驾 驶者对前方的情况很有信心, 而路面的亮度为 $0.5 \mathrm{~cd} / \mathrm{m}^{2}$ 时, 驾驶者对前方的情况仍然有信心, 虽有个别驾驶者表示清 晰度有所下降, 但在可接受的范围内。

（4）夜间驾驶者从洞外较暗的环境进入隧道内较亮 的环境, 需要一个视觉适应过程, 因此隧道内的亮度应从 入洞口开始逐渐升高。当驾驶者从洞内驶出洞外时, 同样 需要一个视觉适应过程, 因此出洞口前的隧道亮度应逐渐 降低为 0 , 以便于与洞外无人工照明的亮度环境平顺对接。 当照明系统无法实行无级调光时, 建议入口和出口的一定 距离的隧道亮度可调至 $0.5 \mathrm{~cd} / \mathrm{m}^{2}$ 。

表2 路面平均亮度 $1.0 \mathrm{~cd} / \mathrm{m}^{2}$ 试验结果分析。

\begin{tabular}{|c|c|c|c|c|c|c|c|}
\hline \multirow{2}{*}{$\begin{array}{l}\text { 测试者 } \\
\text { 编号 }\end{array}$} & \multicolumn{4}{|c|}{ 关闭远光灯 } & \multicolumn{3}{|l|}{ 开启远光灯 } \\
\hline & 扫视时间 & (ms) & 注视时间 (ms) & 主观感受 & 扫视时间 (ms) & 注视时间 (ms) & 主观感受 \\
\hline 1 & 331 & & 67 & 比较有信心 & 366 & 99 & 比较有信心，较未开启更模糊 \\
\hline 2 & I & & l & / & I & I & 1 \\
\hline 3 & 1 & & / & l & 231 & 66 & 比较有信心 \\
\hline 4 & 288 & & 66 & 有信心 & 134 & 99 & 比较有信心, 较未开启更模糊 \\
\hline 5 & 166 & & 99 & 有信心 & 232 & 99 & 比较有信心，较未开启更模糊 \\
\hline 6 & 133 & & 66 & 比较有信心 & 95 & 99 & 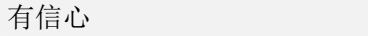 \\
\hline 7 & 275 & & 53 & 1 & 298 & 66 & 有信心 \\
\hline 8 & 131 & & 67 & / & 66 & 66 & 有信心 \\
\hline 9 & 66 & & 66 & 1 & 66 & 99 & 有信心 \\
\hline 10 & 99 & & 180 & 比较有信心 & / & 1 & l \\
\hline 11 & l & & 1 & 有信心 & l & l & / \\
\hline 12 & / & & / & 有信心 & 67 & 65 & 有信心 \\
\hline 13 & 133 & & 69 & 有信心 & 132 & 70 & 比较有信心 \\
\hline 14 & I & & I & 1 & 1 & 1 & / \\
\hline 15 & I & & 1 & 1 & 164 & 66 & 比较有信心 \\
\hline 16 & 68 & & 99 & 有信心 & 138 & 94 & 比较有信心 \\
\hline 17 & 100 & & 99 & 有信心 & 62 & 66 & 有信心 \\
\hline 18 & 99 & & 68 & 有信心 & 213 & 89 & 比较有信心 \\
\hline
\end{tabular}

注: 表格中“”代表实验中该组缺少部分实验数据。

表3 路面平均亮度 $0.5 \mathrm{~cd} / \mathrm{m}^{2}$ 试验结果分析。

\begin{tabular}{|c|c|c|c|c|c|c|}
\hline \multirow{2}{*}{$\begin{array}{l}\text { 测试者 } \\
\text { 编号 }\end{array}$} & \multicolumn{3}{|l|}{ 关闭远光灯 } & \multicolumn{3}{|l|}{ 开启远光灯 } \\
\hline & 扫视时间 (ms) & 注视时间 (ms) & 主观感受 & 扫视时间 (ms) & 注视时间 (ms) & 主观感受 \\
\hline 1 & 99 & 71 & 有信心 & 231 & 66 & 有信心, 较未开启更模糊 \\
\hline 2 & 199 & 66 & 比较有信心 & I & l & I \\
\hline 3 & 397 & 64 & 有信心 & / & / & 1 \\
\hline 4 & / & l & I & 235 & 72 & 有信心, 较未开启更模糊 \\
\hline 5 & 168 & 98 & 比较有信心 & / & / & l \\
\hline 6 & 174 & 91 & 有信心 & 166 & 100 & 有信心 \\
\hline 7 & 167 & 65 & 有信心 & 167 & 65 & 有信心 \\
\hline 8 & 232 & 66 & 有信心 & 235 & 130 & / \\
\hline 9 & 133 & 66 & 有信心 & 236 & 0 & 比较有信心 \\
\hline 10 & 65 & 166 & 有信心 & 166 & 165 & 比较有信心, 较未开启更模糊 \\
\hline 11 & l & / & I & 66 & 199 & 比较有信心，但视野模糊 \\
\hline 13 & 1 & / & / & l & 1 & / \\
\hline 14 & 199 & 68 & 比较有信心 & / & l & 1 \\
\hline 15 & 133 & 66 & 比较有信心 & 166 & 66 & 比较有信心 \\
\hline 16 & 99 & 99 & 有信心 & 1 & / & 1 \\
\hline 17 & 100 & 99 & 有信心 & 166 & 132 & 有信心 \\
\hline 18 & I & l & I & 166 & 99 & 比较有信心 \\
\hline
\end{tabular}

注: 表格中“”代表实验中该组缺少部分实验数据。 


\section{致谢}

本文为国家重点研发计划《城市典型交通基础设施运 维安全关键技术研究》（2017YFC0806003），广西重点 研发计划项目《公路隧道运营安全风险智能防控与应急处 治技术研究》（桂科AB19110019）的阶段性成果之一。

\section{参考文献}

[1] 席海华, 高速公路长隧道出口段夜间照明优化研究[D]. 西安: 长安大学,2009: 25。

[2] 丁光明,刘浩学, 赵炜华. 高速公路长隧道出口段驾驶人视觉 特征变化规律 $[J]$. 长安大学学报:自然科学版,2011(2): 77-80。

[3] 胡英奎, 翁季, 李毅等.道路照明条件下驾驶员瞳孔大小变 化规律 $[J]$.重庆大学学报, 2010,33（8）：85-90。

[4] 王少飞, 邓欣, 吴小丽.公路隧道照明控制技术综述 [J]. 公路 交通技术,2010(02):132-138,146。

[5] 张贤康, 陈绍辉, 张竞奇. 短距离连续公路隧道群光环境 特征及减光措施研究 $[\mathrm{J}]$. 交通节能与环保, 2016, 12(6): 28-31。

[6] 杨春宇, 梁树英, 张青文. 用视觉功效理论研究城市隧道出 入口段与洞外道路照明 [J]. 灯与照明,2012,36(04)：1-4,8。
[7] 王毅才.隧道工程上册(第二版)[M]. 北京: 人民交通出版社, 2007: 136-138。

[8] 赵昕, 刘洋.路表反射率对路面表面温度的研究.[J].科技创 新与运用.2013,30:18-21。

[9] ANSI/IESNA RP-8-00. American National Standards Practice for Roadway Lighting, 2000.

[10] 中华人民共和国行业推荐性标准.JTG/TD70/2-01-2014,公 路隧道照明设计细则 [S]. 北京: 中华人民共和国交通运输部, 2014。

[11] 张青文, 涂耘.基于生理和心理效应的公路隧道入口段照明 质量检测方法.[J].照明工程学报.2012,23:8-14。

[12] 李海琼, 秦雅琴. 眼动仪在道路交通领域中的应用 $[\mathrm{J}]$. 人类工 效学,2012,18(02):75-79.

[13] 胡英奎,陈仲林,张青文,翁季, 黄珂.驾车接近隧道过程中驾 驶员瞳孔大小变化规律 $[\mathrm{J}]$. 土木建筑与环境工 程,2015,37(06):106-113.

[14] 杜志刚,黄发明,严新平,潘晓东.基于睲孔面积变动的公路隧 道明暗适应时间[J]. 公路交通科技,2013,30(05):98-102.

[15] 黄静. 高速公路隧道驾驶员注视点分布特征分析[J].交通科 技,2010(01):91-93.

[16] 王首硕,杜志刚,文竞舟,杨理波.低等级公路光学长隧道驾驶 员视觉负荷研究 [J].隧道建设(中英文),2020,40(02):209-214. 